\title{
Visual and ocular changes associated with exposure to two tertiary amines
}

\author{
E H Page, C K Cook, M A Hater, C A Mueller, A A Grote, V D Mortimer
}

Occup Environ Med 2003;60:69-75

See end of article for authors' affiliations

Correspondence to: Dr E H Page, Division of Surveillance, Hazard Evaluations, and Field Studies, National Institute for Occupational Safety and Health, Centers for Disease Control and

Prevention, 4676 Columbia Parkway, MS R-10, Cincinnati, Ohio 45226-1998, USA; email:edp7@cdc.gov

Accepted 14 June 2002

\begin{abstract}
Aims: To determine if exposure to dimethylisopropanolamine (DMIPA) and dimethylaminoethanol (DMAE) in a label printing plant was associated with visual disturbances and/or ocular changes.

Methods: Questionnaires, eye examinations (visual acuity, contrast sensitivity at $2.5 \%$ and $1.25 \%$ contrast, slit lamp biomicroscopy, and pachymetry), and industrial hygiene monitoring for DMIPA and DMAE were performed over a two week period.

Results: Eighty nine per cent of line workers reported having experienced blurry vision while at work in the past 12 months, compared to $12.5 \%$ of prime workers. A total of 108 full shift personal breathing zone (PBZ) air samples for the amines were collected. The mean time weighted average (TWA) concentration of DMIPA was significantly higher in the line division than in the prime division, as was the mean TWA concentration for total amines. The mean TWA concentration of DMAE was higher in the prime division than the line division. Higher levels of total amines were associated with increased risk of reporting blurry vision, halo vision, and blue-grey vision. The risk of corneal opacity rose with increasing exposure to total amines. The prevalence of corneal opacity also increased with increasing concentration of total amines. Median corneal thickness increased with increasing grades of corneal opacity. There was a statistically significant relation between total amine concentration and increased risk of reduced bilateral visual acuity and $2.5 \%$ contrast sensitivity.

Conclusions: Exposure to tertiary amines was associated with blurry, halo, and blue-grey vision, corneal opacity, and decrements in visual acuity and contrast sensitivity at $2.5 \%$ contrast.
\end{abstract}

The National Institute for Occupational Safety and Health (NIOSH) received a request for a health hazard evaluation from a label printing company. The request stated that employees in the line division of the plant were experiencing intermittent blurred vision, and that one employee had been evaluated by an ophthalmologist who found a "film over his eyes". The blurred vision was described as looking through a fog or a mist. It was most noticeable when looking at lights, causing a halo appearance. The visual changes typically resolved within a couple of hours after leaving work. This had occurred on an intermittent, unpredictable basis, but appeared to have been increasing in frequency. Workers and management had not been able to associate these visual changes with any particular substance in use. The symptoms were reported only by employees in the line division of the plant, only on Mondays to Thursdays, and not on weekends when production was lower.

\section{BACKGROUND}

\section{Facility and process description}

This label printing plant is one of the largest flexographic printing operations for consumer product labelling in the United States. Flexography printing is a form of rotary web letter press that uses flexible rubber plates mounted to a printing cylinder. The production facility opened in 1995. The plant operates two 10-hour shifts on Monday to Thursday, and has only skeleton crews working on Friday to Sunday.

The operation involves printing labels made of paper or plastic materials using water based, ultraviolet (UV), and flourescent inks. Presses are also capable of applying a laminating overprint and adhesive backing at the customer's request. The production area is divided into two divisions, the line division and the prime division. The line division has eight high speed printing presses (approximately 400 feet per minute) that use primarily water based inks (see fig 1). There

\section{Main messages}

- Exposure to DMIPA and DMAE can cause corneal opacity, with resultant decrements in visual acuity and contrast sensitivity.

- These effects, while reversible, pose an immediate safety hazard.

\section{Policy implications}

- Manufacturers of DMIPA and DMAE, or of compounds containing them, should consider listing visual disturbances as an adverse health effect.

is occasional use of fluorescent inks, but no use of UV inks. The prime division has seven printing presses which operate at lower speeds (150-175 feet per minute) and also use mainly water based inks. UV and fluorescent inks are used in the prime division, but less commonly than water based inks. Each press has several five-gallon pails for holding inks before the inks are pumped to ink troughs where plate rolls and cylinders are mounted.

The water based inks contain $1 \%$ dimethylaminoethanol (DMAE) (synonym is dimethylethanolamine) and, depending on the specific ink, varying concentrations of ammonia,

Abbreviations: CFM, cubic feet per minute; $\mathrm{Cl}$, confidence interval; DMAE, dimethylaminoethanol; DMEA, dimethylethylamine; DMIPA, dimethylisopropanolamine; NIOSH, National Institute for Occupational Safety and Health; NMAM, NIOSH Manual of Analytical Methods; OR, odds ratio; $\mathrm{PBZ}$, personal breathing zone; $\mathrm{SF}_{6}$, sulphur hexafluoride; TEA, triethylamine; TWA, time weighted average; UV, ultraviolet 


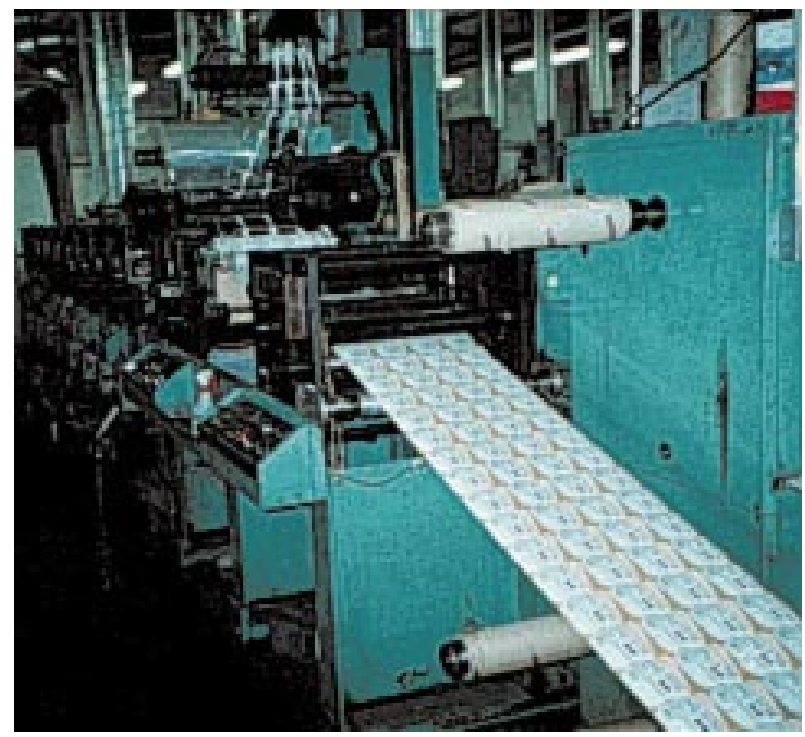

Figure 1 Printing press in the line division of the plant.

isopropyl alcohol, and glycol ether. A compound called clean print additive (containing 45\% DMAE and 55\% water) is used, primarily on the prime side, to increase drying time on the inks. A pH adjuster containing dimethylisopropanolamine (DMIPA) (synonyms dimepranol and 1-dimethylamino-2propanol) is used daily, primarily in the line division. Print additives, such as the $\mathrm{pH}$ adjuster and clean print additive, are manually added to inks stored in the five-gallon pails as needed.

Each press was equipped with blowers to cool UV lamps, and exhaust ventilation to control ozone generated by UV lamps. Conditioned make-up air is supplied to the production areas by fan coil units. The exhaust ducts on the outside of the building had previously terminated on the north wall below the roof line. Concerned that the re-entry of air contaminants from printing presses exhaust back into the building may be causing or contributing to the eye problems, the company had the duct work extended above the roofline. The extensions were configured to curve downward at the end, aiming the discharge towards the surface of the slightly sloped roof.

\section{Amines}

Aliphatic amines are ammonia derivatives in which an alkyl or alkanol group replaces one or more hydrogen atoms. They are classified as primary, secondary, or tertiary amines based on the number of substitutions. They are used as solvents, chemical intermediates, catalysts, preservatives, drugs, and herbicides. ${ }^{1}$

The tertiary amines are irritants to both the skin and mucous membranes. Systemic symptoms related to inhalational exposure to tertiary amines include headache, nausea, and faintness. A number of reports describe blurred vision, halo vision, or blue-grey vision (glaucopsia) among persons exposed to a variety of amines. In all published reports these effects have been reversible. Proposed mechanisms for the visual changes include swelling of the cornea or dilatation of the pupil and paralysis of the ciliary muscle. ${ }^{2}$ The most extensively studied amines are triethylamine (TEA) and dimethylethylamine (DMEA).

Exposure to TEA has been reported to cause the above visual changes in both industrial and experimental settings. ${ }^{3-6}$ Åkesson et al documented pronounced epithelial corneal oedema by slit lamp examination, and increased corneal thickness in two subjects exposed to concentrations of TEA of $48 \mathrm{mg} / \mathrm{m}^{3}$ of air for four hours. ${ }^{4}$ Subjects reported symptoms of foggy vision that started one hour after the onset of exposure, but very minimal discomfort. Similar but less severe findings were noted after exposure to concentrations of TEA of $34 \mathrm{mg} / \mathrm{m}^{3}$ for four hours. In both cases, subjective and objective findings disappeared within hours. In a different experiment, four persons exposed to TEA at concentrations of $40.6 \mathrm{mg} / \mathrm{m}^{3}$ for four hours experienced moderate to severe blurred vision but no eye irritation. ${ }^{6}$ Visual acuity decreased by one row and contrast sensitivity at $2.5 \%$ decreased by one to three rows in three of the four subjects; the fourth had no changes in vision tests. Slit lamp examination showed oedema in the corneal epithelial cells.

In another study, symptoms of foggy vision and blue haze were reported by polyurethane foam production workers exposed to TEA at concentrations of $12-13 \mathrm{mg} / \mathrm{m}^{3}$ of air as an eight hour time weighted average (TWA) with peak concentrations during the sampling period twice that high. ${ }^{5}$ Symptoms resolved within hours of leaving work. Visual acuity, slit lamp examination, and pachymetry were normal at the end of the study period, but were not conducted when workers were symptomatic. It was noted that experimental exposure to similar TWA levels in other studies did not cause similar effects, indicating that exposure to brief peak concentrations may account for at least some of the effects reported by workers.

A study of industrial exposure to TEA in foundry cold box workers measured airborne concentrations ranging from less than 0.3 to $20.3 \mathrm{mg} / \mathrm{m}^{3}$. Symptoms of blurred vision, halo vision, and blue hazy vision were more common in workers with exposure to TEA greater than $10 \mathrm{mg} / \mathrm{m}^{3}$, but this finding was not statistically significant. Corneal thickness did not increase significantly by the end of the shift, either in exposed workers or in symptomatic workers. In another study, Jarvinen and Hyvärinen measured contrast sensitivity of foundry cold box core makers with exposure to TEA. ${ }^{7}$ Contrast sensitivity decreased significantly over the shift, but this did not correlate with concentrations of TEA in the urine. Airborne concentrations of TEA ranged from 0.3 to $60 \mathrm{mg} / \mathrm{m}^{3}$, with very high peak concentrations, suggesting that exposure to high peak concentrations may be responsible for symptoms, or that it may be an "on-off" as opposed to a dose-response phenomenon. The Occupational Safety and Health Administration permissible exposure limit for TEA is $100 \mathrm{mg} / \mathrm{m}^{3}$, and the American Conference of Governmental Industrial Hygienists threshold limit value is $4.14 \mathrm{mg} / \mathrm{m}^{3}$.

Blurred, hazy vision has also been reported with exposure to DMEA. ${ }^{89}$ Symptoms were reported at DMEA concentrations of $6-10 \mathrm{mg} / \mathrm{m}^{3}$ of air as an eight hour TWA, and 25-29 $\mathrm{mg} / \mathrm{m}^{3}$ over 15 minutes in three workers at an aluminium casting foundry. ${ }^{9}$ Workers without symptoms had exposure to concentrations of DMEA over a full shift of up to $24 \mathrm{mg} / \mathrm{m}^{3}$, therefore investigators concluded that the visual disturbances were caused by short term exposures to high peak concentrations of DMEA. Corneal oedema and increased corneal thickness, along with visual disturbances, were noted at airborne concentrations of DMEA of $40-50 \mathrm{mg} / \mathrm{m}^{3}$ over eight hours in human experiments. ${ }^{8}$ The same paper reports that in an occupational setting with median eight hour TWA exposures of 3.5 $\mathrm{mg} / \mathrm{m}^{3}$, two of 12 workers experienced visual symptoms and one had corneal oedema in one eye. These two workers' exposures were about $25 \mathrm{mg} / \mathrm{m}^{3}$ as an eight hour TWA with peak exposures above $100 \mathrm{mg} / \mathrm{m}^{3}$. The authors concluded that the differences between their findings and reports of visual disturbances at lower concentrations in workplace settings may be caused by high peak concentrations in the workplace. There are no occupational exposure limits for DMEA.

DMAE, which is present in the inks used in the study plant, is another tertiary amine. No reports were found in the literature of humans experiencing visual disturbances after exposure to DMAE. However, animal experiments did document corneal opacification, corneal oedema, and ulcerative keratitis at exposures greater than 288 ppm (861 
$\left.\mathrm{mg} / \mathrm{m}^{3}\right) .^{10}$ Exposure to $24 \mathrm{ppm}\left(71.8 \mathrm{mg} / \mathrm{m}^{3}\right)$ resulted in corneal opacity that regressed during non-exposure periods.

DMIPA, which is the primary component of the $\mathrm{pH}$ adjuster used in the study plant, has not been reported to cause visual disturbances in humans. There are no occupational exposure limits for either DMAE or DMIPA.

\section{METHODS Industrial hygiene}

The NIOSH Manual of Analytical Methods (NMAM) No. 2007 is commonly used to monitor amine compounds in air. However, the reliability of the NMAM No. 2007 has been questioned in recent years because this method has a history of yielding non-detectable results even when amine compounds are known to be present in a work environment. The NMAM No. 2007 uses a silica gel $(300 \mathrm{mg} / 150 \mathrm{mg})$ sorbent tube and is believed to inhibit recovery of certain amine compounds after collection from air. Before attempting to collect and analyse numerous air samples using silica gel tubes to assess workers' exposures to DMIPA and DMAE, a NIOSH laboratory conducted a "mini" desorption study on several types of sorbent tubes to determine if a suitable sorbent tube could be found for sampling DMIPA and DMAE. Sorbent tubes that were tested included silica gel, Carbosieve S III, carbon molecular sieve (CMS), XAD-2 resin, and XAD-7 resin. In the desorption study, using methanol as a solvent, DMIPA and DMAE were recovered at the highest rate from XAD-7 tubes, and at the lowest rate from silica gel. Therefore, an air sampling strategy using the XAD-7 tubes was devised for further industrial hygiene monitoring.

For eight workdays comprehensive industrial hygiene monitoring was performed to assess workers' full shift and short term exposures to DMIPA and DMAE. A total of 108 full shift personal breathing zone (PBZ) air samples for the amines were collected, 93 in the line division and 15 in the prime division. Twelve area air samples were collected in the office area of the plant and outdoors. Each air sample was collected on an XAD-7 tube connected to air sampling pumps pre- and post-calibrated at $100 \mathrm{cc} / \mathrm{min}$ of air per min. In accordance with NMAM No. 2007, each sample collected was analysed for both DMIPA and DMAE by gas chromatography equipped with a flame ionisation detector.

\section{Ventilation}

A qualitative assessment of the ventilation system was performed by releasing a glycol based aerosol "fog" from the new exhaust discharge location on top of the roof on the north side of the building and from below the roof line, high on the north outside wall of the building, simulating the previous exhaust discharge location. The fog was observed and videotaped.

A tracer gas study was conducted to quantitatively determine if exhaust re-entered the plant through air intake grilles located close to the exhaust discharges on the north side of the building. Ten MIRAN-203 infrared specific vapour analysers, three B\&K-1302 photoacoustic infrared multi-gas monitors, and an INOVA-1312 photoacoustic multi-gas monitor were positioned inside the plant. Six instruments (four MIRANs, a B\&K, and the INOVA) were placed at widely separated locations in the line division, one MIRAN was located in the office area, two MIRANs were placed near the shredder/ compactors in the warehouse area, one MIRAN was placed in the ink area, and two MIRANs and a B\&K were set up in the prime division. One $\mathrm{B} \& \mathrm{~K}$ multi-gas monitor was used for mobile monitoring wherever needed. A low toxicity gas, sulphur hexafluoride $\left(\mathrm{SF}_{6}\right)$ was then released first from the opening of one of the curved exhaust discharges on the roof, then from the previous exhaust discharge location on the side of the building.
Tracer gas was also used inside the building to assess the transport and dispersion contaminants in the line division. With the instruments in the same locations as described above, $\mathrm{SF}_{6}$ was released from a location under one of the supply air inlets in the south centre of the room to simulate re-entry of previously exhausted air.

The concentrations recorded by the instruments were stored in a digital format to be analysed later, both tabulated on computer spreadsheets and visualised on concentration versus time charts. Starting with the known time of $\mathrm{SF}_{6}$ release, the visualised concentration charts were inspected for any increases that could be identified as coming from the released $\mathrm{SF}_{6}$. If peaks were identified, the time between the release of $\mathrm{SF}_{6}$ and the appearance of the peak was noted, as was the duration and magnitude of the peak.

\section{Medical}

All employees in the line division of the plant were recruited to take part in the evaluation. All participants gave written informed consent. Those who were wearing contact lenses at the time of the evaluation were not eligible to participate because of the possibility of absorption of the chemicals into the contacts and because contact lenses can cause changes in the corneal epithelium. ${ }^{6}$ Workers were informed of this in advance so they could discontinue contact lens use in order to participate, if desired. The medical evaluation consisted of a baseline questionnaire to determine whether the worker had blurred or foggy vision, halo vision, or blue-grey vision in the past year, if these symptoms were accompanied by eye irritation, and if they caused difficulty working or driving home. A history of eye disease or injury was obtained as well.

The same baseline questionnaire was administered to workers in the prime division. Workers in the prime division who reported having experienced blurred, halo, or blue-grey vision in the past were asked to participate in the study.

Eye examinations were performed each day from Monday to Thursday at the beginning and end of both shifts. The examination consisted of visual acuity, contrast sensitivity at $2.5 \%$ and $1.2 \%$ contrast, ultrasonic pachymetry to determine corneal thickness, and a slit lamp examination to determine the presence of corneal opacity. Visual acuity and contrast sensitivity were performed at a distance of 10 feet with a luminance level of 125 candelas per square metre (Precision Vision, LaSalle, Illinois). A loss of at least one line or row on the chart was considered a reduction in visual acuity or contrast sensitivity. Corneal thickness was performed using an ultrasonic pachymeter (Sonomed, Inc., Micropach model 200P) reported in $\mathrm{mm}$. Corneal opacity was graded on a scale of 0 (normal or clear), 1 (minimal/mild opacity), 2 (moderate opacity), and 3 (marked opacity). ${ }^{6}$ The slit lamp examinations and pachymetry were conducted by a board certified ophthalmologist. Employees were administered a brief questionnaire at each examination documenting current symptoms. The visual test examiners were unaware of current visual symptoms of employees.

\section{Statistical analysis}

SAS version 8.1 software (SAS Institute, Cary, North Carolina) was used for the statistical analyses. SAS Proc Mixed, which can take into account the multiple measures for some subjects, was used to compare amine exposure means for those in the line and prime divisions, and for those with and without visual symptoms/signs. A $p$ value of $\leqslant 0.05$ was considered statistically significant. SAS Proc Genmod, which also handles repeated measures for subjects, was used to perform logistic regression analyses. Logistic regression was used to examine possible relations between visual symptoms/signs and the amine exposure levels. The OR reflects a per unit increase of $1 \mathrm{mg} / \mathrm{m}^{3}$ in amine concentration. The logistic regression analyses generated an odds ratio (OR) as a measure 
Table 1 Full shift personal breathing zone concentrations for amines by location (in $\mathrm{mg} / \mathrm{m}^{3}$ )

\begin{tabular}{|c|c|c|c|c|}
\hline & \multicolumn{2}{|c|}{ Line $(n=93)$} & \multicolumn{2}{|c|}{ Prime $(n=15)$} \\
\hline & Mean & Range & Mean & Range \\
\hline Dimethylaminoethanol (DMAE)* & 2.27 & $0.18-3.39$ & 3.47 & $1.71-5.16$ \\
\hline Dimethylisopropanolamine (DMIPA)* & 7.70 & $0.66-17.08$ & 2.08 & $0.86-3.31$ \\
\hline Total amines* & 9.96 & $0.84-20.34$ & 5.56 & $2.71-8.47$ \\
\hline
\end{tabular}

of association. Odds ratios greater than one indicate a positive relation between a symptom/sign and an amine exposure level. Together with the OR, a 95\% confidence interval (CI) for the OR was calculated. The OR is considered statistically significant if the $95 \%$ CI does not include the number one.

\section{RESULTS}

\section{Industrial hygiene}

Table 1 summarises the full shift PBZ air sampling results. The mean TWA concentration of DMIPA was significantly higher in the line division than in the prime division $(7.70 \vee 2.08$ $\left.\mathrm{mg} / \mathrm{m}^{3}, \mathrm{p}<0.01\right)$, as was the mean TWA concentration for total amines $\left(9.96 \vee 5.56 \mathrm{mg} / \mathrm{m}^{3}, \mathrm{p}<0.01\right)$. The mean TWA concentration of DMAE was higher in the prime division than the line division $\left(3.47 \times 2.27 \mathrm{mg} / \mathrm{m}^{3}, \mathrm{p}<0.01\right)$. Total amine TWA concentrations in the office areas ranged from 0.2 to 1.9 $\mathrm{mg} / \mathrm{m}^{3}$ and were non-detectable outdoors.

\section{Ventilation}

From the outside, the smoke-like fog revealed that air flowed into the plant through all doorways. Inside the plant, air flowed into the line division from all surrounding areas. Within the line division, air moved from the southeast corner to the north and east where the label printing equipment local exhaust removed it from the plant.

A small amount of tracer gas $\left(\mathrm{SF}_{6}\right)$ was detected inside the building following both outside releases. However, because of the inability to determine a concentration of tracer gas in the outdoor air in the unbounded vicinity of the air intakes, in the presence of variable, wind-driven air currents, a numerically accurate quantification of the amount of contaminant re-entering the building could not be calculated.

A much greater response of the instruments resulted when tracer gas was released inside the building. An air exchange rate of 1.2 air changes per hour was calculated from the tracer gas decay curve. Based on a floor area for the line division of over $14000 \mathrm{ft}^{2}$ and an average ceiling height of $20 \mathrm{ft}$, the ventilation rate for the line side is estimated at approximately 6000 cubic feet per minute (CFM).

\section{Medical}

One hundred per cent of line and prime workers present at the time of the study filled out the baseline questionnaire, 24 from the prime division and 36 from the line division of the plant. Eighty nine per cent of line workers reported having experienced blurry vision while at work in the past 12 months, compared to $12.5 \%$ of prime workers $(\mathrm{p}<0.01)$. Findings were similar for halo and blue-grey vision, with $72 \%$ of line workers reporting halo vision compared to $8 \%$ of prime workers $(p<0.01)$, and $14 \%$ of line workers reporting blue-grey vision compared to $0 \%$ of prime workers $(p=0.08)$. None of the workers reported medical conditions that would affect their vision. Forty seven per cent of those reporting blurry, halo, or blue-grey vision experienced eye irritation along with the visual changes, $44 \%$ reported difficulty performing their job as a result of the visual changes, and 39\% reported difficulty driving home.
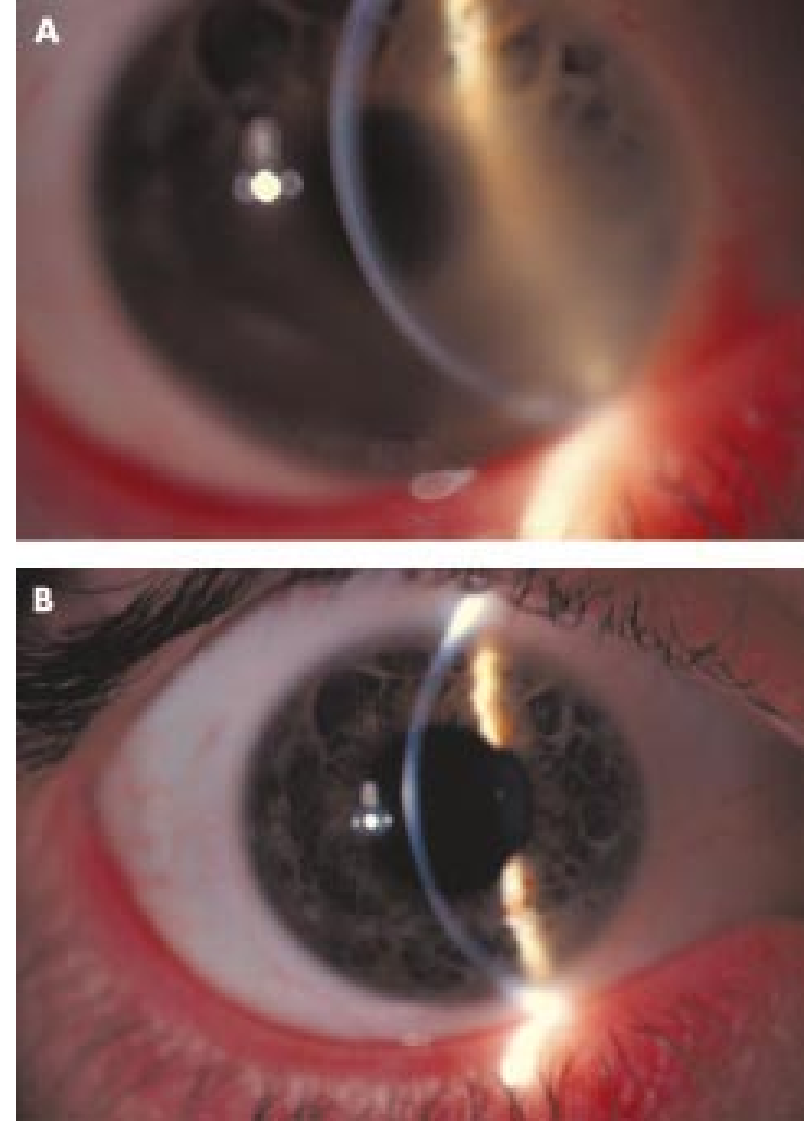

Figure 2 (A) Cornea with grade 3 opacity at end of shift. (B) Same cornea (grade 0 opacity) 14 hours later, prior to next shift.

Three of the 24 prime workers reported blurry vision while at work and therefore participated in the remainder of the study for at least one day. Twenty seven of the 36 line workers participated in the remainder of the study for at least one full day. Therefore, 30 workers participated from one to four days each, for a total of 96 observations. Each observation includes both pre- and post-shift eye examinationss and environmental sampling. No workers declined to participate because of contact lens use.

None of the participants had any corneal opacity at the beginning of the shift on any day. Baseline, or beginning of shift, bilateral visual acuity was 10/10 or better, bilateral contrast sensitivity at $2.5 \%$ contrast was $10 / 32$ or better, and bilateral contrast sensitivity at $1.25 \%$ contrast was $10 / 50$ or better for all participants. During the course of the study, there were 43 episodes of blurred vision reported, 20 episodes of halo vision, and 15 episodes of blue-grey vision. All reports of halo or blue-grey vision occurred in workers who also reported blurry vision; however, the converse is not true. Symptoms developed an average of 4.3 hours after the beginning of the shift. There were 16 episodes of decreased (defined as loss of 
Table 2 Prevalence of reported visual symptoms by total amine concentrations

\begin{tabular}{lcccl}
\hline $\begin{array}{l}\text { Full shift total amine concentrations } \\
\left(\mathrm{mg} / \mathrm{m}^{3}\right)^{*}\end{array}$ & $\mathrm{n}$ & Blurry vision & Halo vision & Blue-grey vision \\
\hline $0.84-7.30$ & 26 & $3(12 \%)$ & $1(4 \%)$ & $0(0 \%)$ \\
$7.31-13.80$ & 57 & $26(46 \%)$ & $11(19 \%)$ & $7(12 \%)$ \\
$13.81-20.33$ & 13 & $12(92 \%)$ & $7(54 \%)$ & $8(62 \%)$ \\
\hline
\end{tabular}

*Range was divided into three groups of equal width.

Table 3 Corneal changes across shift by total amine concentration

\begin{tabular}{llcllll}
\hline $\begin{array}{l}\text { Full shift total amine } \\
\text { concentrations }\left(\mathrm{mg} / \mathrm{m}^{3}\right)\end{array}$ & $\mathrm{n}$ & $\begin{array}{l}\text { Presence of } \\
\text { corneal opacity } \\
\text { in either eye* }\end{array}$ & $\begin{array}{l}\text { Prevalence of } \\
\text { increased corneal } \\
\text { thickness either eye }\end{array}$ & $\begin{array}{l}\text { Mean change in } \\
\text { corneal thickness } \\
(\mathrm{mm})(\mathrm{SD})\end{array}$ & $\begin{array}{l}\text { Median change in } \\
\text { corneal thickness } \\
\text { (mm) }\end{array}$ & $\begin{array}{l}\text { Range of change in corneal } \\
\text { thickness (mm) }\end{array}$ \\
\hline $0.84-7.30$ & 26 & $3(12 \%)$ & $17(65 \%)$ & $-0.0015(0.0073)$ & 0.0003 & -0.0250 to 0.0055 \\
$7.31-13.80$ & 57 & $13(23 \%)$ & $39(68 \%)$ & $0.0004(0.0060)$ & 0.0010 & -0.0155 to 0.0200 \\
$13.81-20.33$ & 13 & $8(62 \%)$ & $12(92 \%)$ & $0.0065(0.0087)$ & 0.0050 & -0.0055 to 0.0285 \\
\hline
\end{tabular}

*Either grade 1, 2, or 3 .

Table 4 Corneal thickness changes across shift by corneal opacity

\begin{tabular}{|c|c|c|c|c|c|c|c|c|}
\hline \multirow{2}{*}{$\begin{array}{l}\text { Corneal opacity } \\
\text { grade }\end{array}$} & \multicolumn{4}{|c|}{ Change in corneal thickness, left eye $(\mathrm{mm})$} & \multicolumn{4}{|c|}{ Change in corneal thickness, right eye $(\mathrm{mm})$} \\
\hline & $\mathrm{n}$ & Mean & Median & Range & $\mathrm{n}$ & Mean & Median & Range \\
\hline 0 & 77 & -0.0006 & 0.001 & -0.028 to 0.013 & 76 & -0.0005 & 0.0005 & -0.022 to 0.015 \\
\hline 1 & 16 & 0.003 & 0.003 & -0.008 to 0.017 & 13 & 0.004 & 0.001 & -0.004 to 0.017 \\
\hline 2 & 5 & 0.007 & 0.010 & -0.005 to 0.018 & 9 & 0.004 & 0.005 & -0.006 to 0.022 \\
\hline 3 & 2 & 0.022 & 0.022 & 0.018 to 0.026 & 2 & 0.021 & 0.021 & 0.011 to 0.031 \\
\hline
\end{tabular}

Table 5 Prevalence of across-shift decrements in vision by total amine concentration

\begin{tabular}{lllcr}
\hline $\begin{array}{l}\text { Full shift total amine } \\
\text { concentrations }\left(\mathrm{mg} / \mathrm{m}^{3}\right)\end{array}$ & $\mathrm{n}$ & $\begin{array}{l}\text { Decreased bilateral } \\
\text { visual acuity }\end{array}$ & $\begin{array}{l}\text { Decreased bilateral contrast } \\
\text { sensitivity at 2.5\% contrast }\end{array}$ & $\begin{array}{c}\text { Decreased bilateral contrast } \\
\text { sensitivity at 1.25\% contrast }\end{array}$ \\
\hline $0.84-7.30$ & 26 & $2(8 \%)$ & $1(4 \%)$ & $9(35 \%)$ \\
$7.31-13.80$ & 57 & $7(12 \%)$ & $11(19 \%)$ & $19(33 \%)$ \\
$13.81-20.33$ & 13 & $6(46 \%)$ & $8(62 \%)$ & $6(46 \%)$ \\
\hline
\end{tabular}

one row or more) bilateral visual acuity, 22 episodes of decreased bilateral contrast sensitivity at $2.5 \%$ contrast, and 35 episodes of decreased bilateral contrast sensitivity at $1.25 \%$ contrast. Decrements in bilateral visual acuity ranged from one to two rows, decrements in bilateral contrast sensitivity at $2.5 \%$ contrast ranged from one to eight rows, and at $1.25 \%$ ranged from one to six rows. There were 23 observations of corneal opacity in the left eye ( 16 were grade 1 , five were grade 2 , and two were grade 3 ) and 24 in the right eye (13 were grade 1 , nine were grade 2 , and two were grade 3 ) at the end of the shift. In all instances of corneal opacity, there was complete clearing by the beginning of the worker's next shift (see fig 2).

There was a positive association between reported visual symptoms and PBZ concentrations of total amines. Exposures to higher levels of total amines were associated with increased risk of reporting blurry vision (OR $1.78,95 \%$ CI 1.41 to 2.26 ), halo vision (OR 1.38, 95\% CI 1.20 to 1.58 ), and blue-grey vision (OR 1.77, 95\% CI 1.31 to 2.39 ) at the end of a shift. All OR reported in this paper reflect a per unit increase of $1 \mathrm{mg} / \mathrm{m}^{3}$ in amine concentration. Symptom reporting increased with exposure to increasing concentrations of amines (table 2). Results were similar when evaluating the relation between symptom reporting and exposure to the individual amines (DMIPA and DMAE).
The risk of developing corneal opacity over a shift rose with increasing exposure to total amines (OR 1.15, 95\% CI 1.02 to 1.30). The prevalence of corneal opacity also increased with exposure to increasing concentrations of total amines (table 3). Similar results were found when evaluating exposure to DMIPA and DMAE separately.

The prevalence of increased corneal thickness in either eye over a shift increased with higher levels of exposure to total amines, as did both the mean and median changes in thickness (table 3 ). There was a positive association between increases in across-shift corneal thickness and concentrations of total amines; however, it was not statistically significant (OR 1.08, 95\% CI 0.95 to 1.23). Results were similar when evaluating exposure to DMIPA and DMAE separately, and when looking at each eye individually. Median corneal thickness increased with increasing grades of corneal opacity (table 4).

There was a statistically significant relation between total amine concentration and increased risk of reductions in bilateral visual acuity and contrast sensitivity at $2.5 \%$ contrast over a shift (OR 1.2, 95\% CI 1.001 to 1.43 ; OR $1.28,95 \%$ CI 1.14 to 1.43 , respectively). Similar results were found for DMIPA and DMAE separately, but were not statistically significant for DMAE. There was not a significant association between 
reduced contrast sensitivity at $1.25 \%$ contrast and concentrations of total amines, DMAE, or DMIPA. Table 5 depicts the prevalence of decrements in visual acuity and contrast sensitivity at $2.5 \%$ and $1.25 \%$ contrast by concentration of total amines.

\section{DISCUSSION}

There have been case reports of blurry, halo, and/or blue-grey vision in workers exposed to a variety of amines. Experimental exposure to TEA and DMEA produced visual symptoms, increased corneal thickness, corneal oedema, and decrements in visual acuity and contrast sensitivity in study subjects. ${ }^{468} \mathrm{In}$ contrast, industrial studies have failed to associate these findings with average exposures to DMEA and TEA. ${ }^{378}$ It has been postulated that this is because visual findings may be caused by high peak exposures to amines as opposed to average exposures.

We documented an association between symptoms of blurry, halo, and blue-grey vision, corneal opacity, decrements in visual acuity, and contrast sensitivity at $2.5 \%$ contrast and TWA exposure to two tertiary amines, DMAE and DMIPA. Neither DMAE nor DMIPA have previously been reported to cause visual disturbances in humans. Concentrations of DMAE and DMIPA were highly correlated, making it difficult to separate the effects of each amine. In addition, the two compounds are very similar, and it would be expected that they would produce similar health effects. However, DMIPA is the amine most likely to be causing visual changes in this group of workers for several reasons. Visual symptoms were much more common in the line division, where concentrations of DMAE were significantly lower than in the prime division. In contrast, DMIPA concentrations were significantly higher in the line division. Overall, DMIPA was present at levels approximately 3-4 times higher than DMAE. DMIPA is more volatile than DMAE, with a vapour pressure of 14.7 torr compared to 4.0 torr for DMAE. ${ }^{11}$ Plant management reports that they have been diluting the $\mathrm{pH}$ adjuster with water since discovering it might be the cause of employees' visual disturbances, and that there have been no complaints since taking this action. NIOSH investigators interviewed 27 of the 36 $(75 \%)$ line division workers who participated in the study (the other nine were not at work at the time of the interviews) to confirm the cessation of visual disturbances. All 27 employees reported they had not experienced any visual disturbances since the process of diluting the $\mathrm{pH}$ adjuster had been in place, and had not heard any other employees report visual disturbances.

In the previous studies of both human and animal subjects exposed to tertiary amines other than DMIPA and DMAE, investigators have used terms such as toxicity and corneal oedema. ${ }^{4810}$ This implies that the amines directly injure the corneal epithelium, resulting in cellular dysfunction and swelling. Some of the studies have shown increased corneal thickness, while others have not. ${ }^{3}$ However, our study's observations also support another mechanism, that of direct deposition of tertiary amines into the corneal epithelium without significant cellular dysfunction or toxicity. The opacity caused by direct deposition might be the result of incomplete solubility of tertiary amines into the corneal epithelium. The corneal epithelium is a highly lipophilic tissue, and tertiary amines are typically largely hydrophilic and water soluble. Several observations in this study may support the hypothesis of direct deposition as the mechanism of producing opacity. First, there was a minimal increase in corneal thickness in those subjects with corneal opacity. This implies a lack of endothelial dysfunction, and a lack of stromal oedema. Other studies have similarly noted a lack of endothelial cell dysfunction. ${ }^{4}{ }^{6}$ The corneal opacity was more prominent inferiorly, in the interpalbebral fissure, where classically environmental exposure is greatest (as opposed to superiorly, where the upper lid imparts partial protection to the epithelium). Other studies have noted this localised effect with exposure to different amines. ${ }^{48}$ The clinical appearance of the opacity was also different from true epithelial oedema. Typical oedema causes an increase in the intercellular fluid content of the epithelium, resulting in cyst-like spaces, called microcystic oedema. None of the subjects in this evaluation showed microcystic changes, but rather a diffuse and uniform opacity. With toxic effects, rapid cell death and epithelial shedding often occur, resulting in punctate corneal erosions or frank epithelial defects. However, none of the subjects in this study showed any increase in loss of epithelial cells. In fact, all subjects, once removed from the workplace, showed rapid reversibility of the opacity, with complete clearing by the next day and complete recovery to baseline vision, corneal thickness, and corneal clarity. There were no apparent cumulative effects or long term corneal injury. However, there may have been insufficient person-time to fully exclude long term toxicity to the cornea. Finally, the subjects in this study reported a fairly mild degree of irritation and did not show any conjunctival inflammation, which would be expected with epithelial toxicity given the typically painful presentation of microcystic oedema because of the rich supply of corneal pain receptors. This does not mean that DMIPA and DMAE are completely non-toxic to the cornea, but means that at the concentrations seen in this study, toxicity in the classic sense did not seem to occur. Further studies involving the behaviour of the cornea at various concentrations of representative tertiary amines would be of great value. Additionally, histological examination of animal corneas after exposure would be of use in assessing the various levels of teriary amine penetration, the presence or absence of true oedema, and the degree, if any, of tissue damage on a cellular level.

Re-entry of air exhausted from the printing machines was not determined to be a problem on the day of the tracer gas testing as the amount of $\mathrm{SF}_{6}$ re-entering the building was so small as to be barely detectable. However, on that day, the wind blowing from the north would have carried exhausted $\mathrm{SF}_{6}$ away from the outdoor air intakes and entry points to the building. On the day the aerosol "fog" was used to visualise the movement of air around the exhaust discharges and building air intakes, the wind was out of the south; and, although most of the smoke was carried away from the building, some "fog" was observed circulating into the area of the outdoor air intakes. For this reason, it is expected that re-entry would be more of a problem with prevailing winds from the south, which is typical for this area of the country.

Inside the building, the tracer gas spread quickly throughout the line division when released from a central point in that area. It also dispersed quickly from the sampling locations. For 25-30 workers per shift on the line side, the ventilation rate was approximately 200 CFM per person, suggesting an adequate amount of outside air. There are no specific standards for general ventilation in a manufacturing plant such as this other than a guideline minimum of 15 CFM per person of outdoor air. It is, however, essential that the incoming outdoor air does not contain high concentrations of environmental contaminants, including those previously exhausted from the building. Recommendations were made to improve local exhaust ventilation, and to reposition the exhaust discharges and air intakes to prevent/reduce entry of exhausted contaminants back into the building. It was recommended that local exhaust ventilation be ducted to discharges on the outside of the building as close to the northeast corner of the building as practicable. If more that one discharge duct exits the building, the exhaust discharges should be grouped tightly together to take advantage of the larger effective diameter of the combined jet to achieve greater plume height. The discharge ductwork should extend at least 6 feet above the edge of the roof on the north side of the building and have a diameter such that the exhaust exits the 
end of each duct at a velocity not less than $2000 \mathrm{ft} / \mathrm{min}$ and not greater than $3000 \mathrm{ft} / \mathrm{min}$. The outdoor air intakes should be located as far to the west of the exhaust discharge point as practicable.

\section{CONCLUSIONS}

Exposure to tertiary amines in this plant was associated with blurry, halo, and blue-grey vision, corneal opacity, and decrements in visual acuity and contrast sensitivity at $2.5 \%$ contrast. While this appears to be a reversible phenomenon, the visual changes pose a safety hazard, both on the job and when driving home. Dilution of the $\mathrm{pH}$ adjuster, which decreases the concentration of DMIPA and thus employee exposure, has eliminated employee reports of visual disturbances.

The re-entry of exhausted air is a potential problem, and the ventilation in the line division is not adequate under current work practices. Although increasing the general ventilation may provide some reduction in exposure, a more cost effective solution would be to improve the local exhaust ventilation controlling the sources of tertiary amines associated with the printing machines, and then to also reposition the outdoor air intakes and exhaust discharge locations.

\section{Authors' affiliations}

E H Page, C K Cook, C A Mueller, V D Mortimer, Division of Surveillance, Hazard Evaluations, and Field Studies, National Institute for Occupational Safety and Health, Centers for Disease Control and Prevention, 4676 Columbia Parkway, MS R-10, Cincinnati, Ohio 45226-1998, USA
M A Hater, Cincinnati Eye Institute

A A Grote, Division of Applied Research Technology, National Institute for Occupational Safety and Health

We attest that this article was prepared by US government employees as part of their official duties and legally may not be copyrighted

\section{REFERENCES}

1 Rosenberg J, Cone JE, Katz EA. Solvents. Chapter 29. In: LaDou J, ed. Occupational and environmental medicine, 2nd edn. Stamford, CT: Appleton and Lange, 1997:483-513.

2 Albrecht WN, Stephenson RL. Health hazards of tertiary amine catalysts. Scand J Work Environ Health 1988;14:209-19.

3 Reilly MJ, Rosenman KD, Abrams JH, et al. Ocular effects of exposure to triethylamine in the sand core cold box of a foundry. Occup Environ Med 1995;52:337-43

4 Åkesson B, Florén I, Skerfving S. Visual disturbances after experimental human exposure to triethylamine. $\mathrm{Br} J$ Ind Med 1985;42:848-50.

5 Åkesson B, Bengtsson M, Florén I. Visual disturbances after industrial triethylamine exposure. Int Arch Occup Environ Health 1986;57:297-302

6 Jarvinen P, Engstrom K, Riihmaki V, et al. Effects of experimental exposure to triethylamine on vision and the eye. Occup Environ Med 1999;56:1-5.

7 Jarvinen P, Hyvärinen L. Contrast sensitivity measurement in evaluations of visual symptoms caused by exposure to triethylamine. Occup Environ Med 1997;54:483-6.

8 Stählbom B, Lundh T, Florén I, et al. Visual disturbances in man as a result of experimental and occupational exposure to dimethylamine. $\mathrm{Br} \mathrm{J}$ Ind Med 1991:48:26-9.

9 NIOSH. Request for assistance in preventing vision disturbances and acute physical distress due to dimethylethylamine (DMEA) exposure. Cincinnati, OH: US Department of Health and Human Services, Public Health Service, Centers for Disease Control, National Institute for Occupational Safety and Health, DHHS (NIOSH) Publication No. 88-103, 1987.

10 Klonne DR, Dodd DE, Pritts IM, et al. Dimethylethanolamine: acute, 2-week, and 13-week inhalation toxicity studies in rats. Fundam Appl Toxicol 1987;9:512-21.

11 Ballantyne B, Leung $H$. Acute toxicity and primary irritancy of alkylalkanolamines. Vet Human Toxicol 1996;38:422-6.

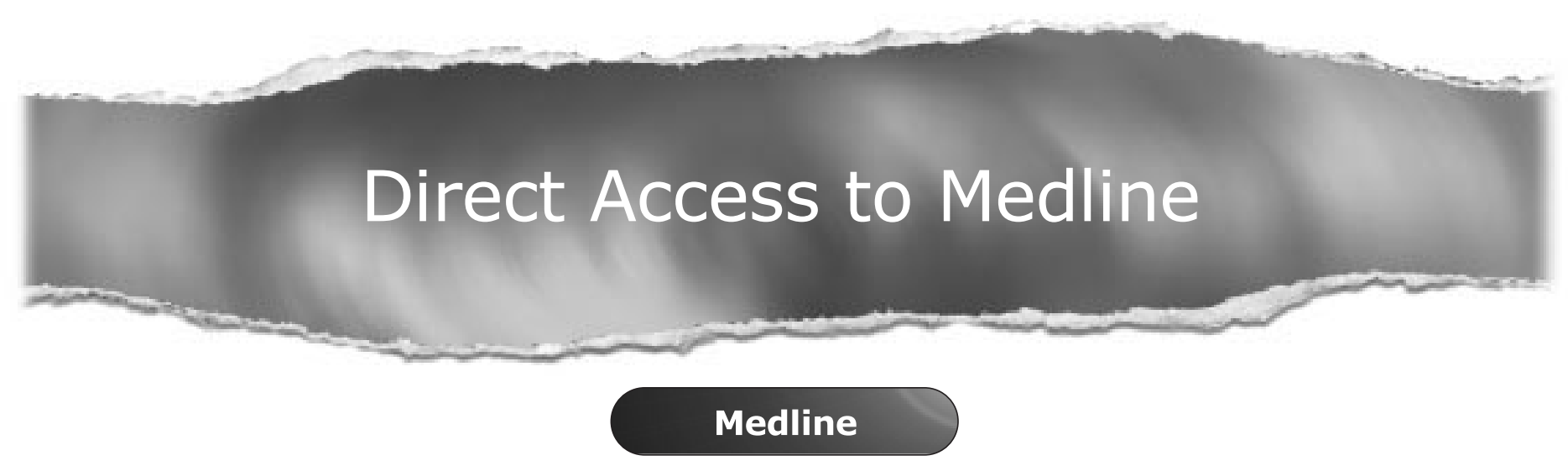

Link to Medline from the homepage and get straight into the National Library of Medicine's premier bibliographic database. Medline allows you to search across 9 million records of bibliographic citations and author abstracts from approximately 3,900 current biomedical journals.

www.occenvmed.com 